\title{
Níveis de fibra em detergente neutro na dieta de cordeiros: consumo, digestibilidade e fermentação ruminal.
}

\author{
[Levels of neutral detergent fiber in lambs diets: intake, digestibility and ruminal fermentation]
}

\author{
G.V. Kozloski, L.M. Trevisan, L.M. Bonnecarrère, C.J. Härter, G. Fiorentini, \\ D.B. Galvani, C.C.Pires
}

\author{
Departamento de Zootecnia - UFSM \\ Campus Camobi \\ 97105-900 - Santa Maria, RS
}

\begin{abstract}
RESUMO
Foram utilizados oito cordeiros castrados $(35,0 \pm 6,0 \mathrm{~kg}$ peso vivo) em um delineamento duplo quadrado latino $4 \times 4$ para avaliar o efeito de quatro níveis de fibra em detergente neutro (FDN) na dieta $(25,31,37$ e $43 \%$ da matéria seca (MS)) sobre o consumo e parâmetros digestivos. O consumo de nitrogênio $(\mathrm{N})$ variou de forma quadrática; o de MS, matéria orgânica $(\mathrm{MO})$ e energia diminuíram $(\mathrm{P}<0,05)$ e de FDN aumentou $(\mathrm{P}<0,01)$ linearmente com o aumento de fibra na dieta. A digestibilidade da FDN e do $\mathrm{N}$, assim como o $\mathrm{pH}$ e as concentrações de peptídeos no fluído ruminal foram similares em todos os tratamentos. A digestibilidade aparente da MS, da MO e da energia, assim como as concentrações ruminais de açúcares diminuíram linearmente $(\mathrm{P}<0,01)$ e a síntese de proteína microbiana ruminal, as concentrações ruminais de amônia e de aminoácidos variaram quadraticamente $(\mathrm{P}<0,05)$ com o aumento do teor de FDN das dietas. A redução do consumo e da digestibilidade foram mais evidentes somente pela inclusão do nível mais alto de FDN (43\%) e, sob o aspecto nutricional, a inclusão em torno de $30 \%$ de FDN representa o nível mais adequado para formulação de dietas a base de silagem de sorgo e concentrado oferecido a cordeiros confinados.
\end{abstract}

Palavras-chave: concentrado, cordeiros, eficiência alimentar, nível de fibra, volumoso

\begin{abstract}
Eight castrated raw lambs $(35.0 \pm 6.0 \mathrm{~kg}$ live weight) were used in a replicated $4 \times 4$ latin square design to evaluate the effect of four neutral detergent fiber (NDF) levels (25, 31, 37 and 43\% of dry matter (DM)) on intake and digestion traits. Nitrogen $(N)$ intake varied quadratically; intake of DM, organic matter $(O M)$ and energy decreased $(P<0.05)$ and that of $N D F$ increased $(P<0.01)$ as fibre level increased. NDF and $N$ digestibility, as well as $p H$ and ruminal concentrations of peptides were similar for all treatments. Apparent digestibility of DM, OM and energy, as well as ruminal concentrations of sugars decreased $(P<0.01)$ and, ruminal microbial protein synthesis and ruminal concentrations of ammonia and amino acids varied in a quadratic way $(P<0.05)$ with increased levels of $N D F$. The effect of $N D F$ in decreasing intake and digestibillity was more evident only at the highest level (43\%). The inclusion of about $30 \%$ $N D F$ represents the most adequate level for sorghum silage and concentrate based diets fed to feedlot lambs.
\end{abstract}

Keywords: concentrate, lambs, feeding eficiency, fibre level, roughage

Recebido em 10 de fevereiro de 2005

Aceito em 27 de janeiro de 2006

E-mail: kozloski@smail.ufsm.br 


\section{Kozloski et al.}

\section{INTRODUÇÃO}

A ovinocultura de corte tem grande potencial para aumentar a oferta de proteína animal no País. Nesta espécie, a categoria animal que apresenta melhor eficiência alimentar, maiores rendimentos de carcaça e melhor qualidade de carne, por sua maciez e baixos teores de gordura, é o cordeiro (Pires, 2000). Contudo, as taxas de ganho de peso e a qualidade da carne são dependentes também do potencial genético, do consumo e do valor nutricional da dieta oferecida aos animais.

A qualidade da dieta é influenciada por uma série de fatores, entre eles, pelo teor de fibra em detergente neutro (FDN). Esta fração é inversamente relacionada com o consumo e com o teor de energia disponível dos alimentos (Van Soest, 1994). A FDN tem baixa taxa de degradação e lenta taxa de passagem pelo retículo-rúmen e, desta maneira, dietas com altos teores de FDN promovem redução na ingestão de matéria seca total, em função da limitação provocada pelo enchimento do retículo-rúmen, limitando a expressão do potencial genético do animal para produção. Por outro lado, o processo fermentativo ruminal é altamente dependente do $\mathrm{pH}$ do meio, e este por sua vez, está diretamente relacionado com o teor de fibra efetiva da dieta. Estudos in situ (Mould e Orskov, 1983; Tripathi et al., 2004) e in vitro (Grant e Mertens, 1992; Mourino et al., 2001) demonstraram que a atividade celulolítica ruminal e a digestibilidade da fibra são reduzidas com a queda do $\mathrm{pH}$ ruminal, particularmente a valores abaixo de 6,0, e que estes efeitos são acentuados pela presença de carboidratos solúveis no meio.

Os sistemas nutricionais mais recentes, como o Cornell Net Carbohydrate and Protein System (CNCPS) para bovinos (Fox et al., 2004) e ovinos (Cannas et al., 2004) estabeleceram exigências mínimas para níveis de FDN nas dietas (entre 20 e $24,5 \%$ de FDN), abaixo dos quais a fermentação e a síntese de proteína microbiana ruminal seriam negativamente alterados. No entanto, possíveis efeitos de níveis de FDN acima daqueles limites mínimos não são considerados. Deste modo, o objetivo do presente trabalho foi avaliar o efeito de diferentes níveis de FDN sobre o consumo e sobre a digestão em cordeiros alimentados com dietas a base de silagem de sorgo e, adicionalmente, verificar se há um nível ótimo de fibra que otimize a utilização do alimento pelos animais.

\section{MATERIAL E MÉTODOS}

Foram utilizados oito cordeiros mestiços Texel, Corriedale e Ile de France (peso vivo médio de $35,0 \pm 6,0 \mathrm{~kg}$ ), sendo quatro fistulados no rúmen, mantidos em gaiolas metabólicas, em um delineamento experimental duplo quadrado latino $4 \times 4$ para avaliar o efeito de quatro níveis de FDN na dieta $(25,31,37$ e $43 \%$ da matéria seca) sobre o consumo voluntário, a fermentação ruminal, a síntese de proteína microbiana ruminal e sobre a digestibilidade. Cada parcela, correspondente a animal-período, foi representada por dois animais. $\mathrm{O}$ experimento foi conduzido em quatro períodos de 15 dias, sendo 10 dias de adaptação às dietas e cinco dias de coleta de amostras. Os animais foram pesados no início e no final de cada período experimental, após jejum absoluto de aproximadamente 16 horas.

Os animais foram alimentados à vontade (de modo a ter sobras em torno de $10 \%$ do oferecido) com dietas a base de silagem de sorgo e diferentes tipos e proporções de concentrado, fornecidos misturados no cocho, de modo a obter dietas isonitrogenadas e com os níveis de FDN propostos. A formulação dos concentrados e a composição química das dietas são apresentadas nas Tab. 1 e 2 , respectivamente.

As quantidades oferecidas e as sobras foram mensuradas diariamente durante todo o período experimental. Nos últimos cinco dias de cada período foi feita a coleta total das fezes e da urina, as quais foram pesadas e mensuradas pelo volume, respectivamente. A urina foi coletada em frascos contendo $100 \mathrm{ml}$ de uma solução de ácido sulfúrico a $20 \%(\mathrm{v} / \mathrm{v})$. Amostras de fezes (aproximadamente $10 \%$ do total) e de urina ( $1 \%$ do volume total) foram coletadas diariamente. As amostras de fezes foram secadas a $55^{\circ} \mathrm{C}$ em estufa de ar forçado durante pelo menos 72 horas, moídas (peneira de $1 \mathrm{~mm}$ ) e armazenadas para posterior análise. As amostras de urina foram diluídas com água destilada para completar um volume de $50 \mathrm{ml}$ e congeladas ($20^{\circ} \mathrm{C}$ ) para posterior análise. As amostras diárias das sobras, das fezes e da urina foram compostas por animal e por período. 
Níveis de fibra em detergente neutro na dieta...

Tabela 1. Formulação (kg, base matéria seca) dos concentrados

\begin{tabular}{lcccc} 
& \multicolumn{4}{c}{ Tratamentos (\% de FDN na MS) } \\
\cline { 2 - 5 } & $25 \%$ & $31 \%$ & $37 \%$ & $43 \%$ \\
\hline Milho & 72,5 & 63,6 & 47,2 & 6,7 \\
Farelo de soja & 25,2 & 33,6 & 49,1 & 87,5 \\
Sal comum & 0,8 & 1,0 & 1,5 & 2,6 \\
Calcáreo calcítico & 1,5 & 1,6 & 1,7 & 1,9 \\
Fosfato bicálcico & 0 & 0,2 & 0,5 & 1,3 \\
\hline
\end{tabular}

Tabela 2. Composição química ${ }^{1}$ da silagem e dos concentrados nos diferentes tratamentos

\begin{tabular}{|c|c|c|c|c|c|}
\hline & \multirow{2}{*}{$\begin{array}{l}\text { Silagem } \\
\text { de sorgo }\end{array}$} & \multicolumn{4}{|c|}{ Concentrados } \\
\hline & & $25 \%$ & $31 \%$ & $37 \%$ & $43 \%$ \\
\hline MS (\%) & 27,6 & 84,5 & 85,2 & 84,7 & 85,8 \\
\hline \multicolumn{6}{|c|}{ Composição como \% da MS } \\
\hline MO & 94,9 & 94,9 & 94,3 & 94,4 & 91,0 \\
\hline FDN & 56,2 & 12,2 & 11,4 & 11,9 & 15,6 \\
\hline FDA & 29,2 & 6,3 & 6,5 & 7,5 & 8,4 \\
\hline LDA & 4,6 & 1,1 & 1,0 & 0,8 & 1,3 \\
\hline $\mathrm{EE}$ & 2,7 & 3,0 & 2,6 & 2,7 & 2,7 \\
\hline $\mathrm{CNF}^{2}$ & 31,7 & 60,2 & 54,7 & 48,7 & 31,0 \\
\hline $\mathrm{N}$ total & 1,0 & 3,3 & 4,2 & 5,2 & 6,8 \\
\hline \multicolumn{6}{|c|}{ Composição como \% do $\mathrm{N}$ total } \\
\hline NIDA & 16,2 & 2,4 & 1,2 & 1,3 & 1,2 \\
\hline NIDN & 32,4 & 5,4 & 2,6 & 4,2 & 1,9 \\
\hline
\end{tabular}

MS=matéria seca; $\mathrm{MO}=$ =matéria orgânica; FDN=fibra em detergente neutro; FDA=fibra em detergente ácido, LDA=lignina, $\mathrm{EE}=$ extrato etérico, $\mathrm{CNF}=$ carboidratos não fibrosos; $\mathrm{N}=$ nitrogênio, $\mathrm{NIDA}=$ nitrogênio insolúvel em detergente ácido; $\mathrm{NIDN}=$ nitrogênio insolúvel em detergente neutro. ${ }^{2} \mathrm{CNF}=\mathrm{MO}-((\mathrm{N} \times 6,25)+\mathrm{EE}+\mathrm{FDN})$.

Amostras de conteúdo ruminal $( \pm 100 \mathrm{ml})$ foram coletadas no $15^{\circ}$ dia de cada período, nos tempos $0,1,2,3,4,6$ e 8 horas após o fornecimento do alimento da manhã. Imediatamente após a amostragem foi feita a leitura do $\mathrm{pH}$ e, a seguir, duas alíquotas de $18 \mathrm{ml}$ foram coletadas, sendo em uma adicionado $2 \mathrm{ml}$ de uma solução de ácido tricloroacético (TCA) a $50 \%$ e, na outra, adicionado $2 \mathrm{ml}$ de uma solução de $\mathrm{H}_{2} \mathrm{SO}_{4}$ a $20 \%$. Estas amostras permaneceram em temperatura ambiente durante uma hora $\mathrm{e}$ a seguir foram centrifugadas $(4000 \times \mathrm{g}$ por 20minutos). O sobrenadante foi coletado e armazenado em congelador para posterior análise.

Nas amostras do alimento oferecido e nas sobras foi determinado o teor de matéria seca (MS) por secagem em estufa a $105{ }^{\circ} \mathrm{C}$ durante pelo menos 8 horas e as cinzas por queima em mufla a 550 ${ }^{\circ} \mathrm{C}$ durante 2 horas. O teor de nitrogênio total $(\mathrm{N})$ foi determinado por um método Kjeldahl (método 984.13, Official..., 1995), modificado por usar uma solução de ácido bórico $4 \%(\mathrm{p} / \mathrm{v})$ como receptor da amônia livre durante a destilação, uma solução de $0,2 \%(\mathrm{p} / \mathrm{v})$ de verde de bromocresol e $0,1 \%(\mathrm{p} / \mathrm{v})$ de vermelho de metila como indicador, e uma solução padrão de ácido sulfúrico para titulação. Os teores de nitrogênio insolúvel em detergente ácido (NIDA) e em detergente neutro (NIDN) foram determinados de acordo com Licitra et al. (1996) e, os teores de FDN, fibra em detergente ácido (FDA) e lignina em detergente ácido (LDA) de acordo com Robertson e Van Soest (1981). Nas fezes foram determinados os teores de MS, MO, N, FDN e NIDN. Nas amostras de urina foram determinados os derivados das purinas (xantina, hipoxantina, alantoína e ácido úrico) para estimar a síntese de proteína microbiana ruminal (Chen e Gomes, 1995). Nas amostras de fluido ruminal acidificadas com ácido sulfúrico foram determinadas as concentrações de amônia (Weatherburn, 1967) e de açúcares solúveis (Dubois et al., 1956). Naquelas precipitadas com TCA foi determinado o teor de aminoácidos (Palmer e Peters, 1969) antes e após hidrólise ácida $(2 \mathrm{ml}$ de sobrenadante e $2 \mathrm{ml}$ de $\mathrm{HCl} 6 \mathrm{~N}$, adicionados em tubos de vidro com tampa 


\section{Kozloski et al.}

rosqueada), a $120^{\circ} \mathrm{C}$, em autoclave, durante 24 horas. O teor de peptídeos foi calculado como sendo a diferença entre os valores de aminoácidos antes e depois da hidrólise.

Os resultados foram submetidos à análise de variância que incluiu os efeitos dos quadrados latinos, dos animais, dos períodos e dos níveis de FDN obtidos. Para análise dos parâmetros ruminais foram ainda incluídos no modelo os efeitos do tempo após a refeição e da interação tempo x tratamento. Os dados foram também analisados por regressão, sendo que os graus de liberdade dos tratamentos foram separados nos componentes linear e quadrático. Todas as análises foram conduzidas utilizando-se $\mathrm{o}$ programa SAS (User's..., 1996).

\section{RESULTADOS E DISCUSSÃO}

Como esperado, o consumo de MS, MO, EE e CNF diminuiu $(\mathrm{P}<0,05)$ e o de FDN e FDA aumentou $(\mathrm{P}<0,01)$ linearmente com o aumento de fibra na dieta (Tab. 3). Os níveis de fibra obtidos foram inferiores aos pretendidos, com exceção do tratamento com $43 \%$ de FDN. Os alimentos foram fornecidos à vontade, o que permitiu aos animais selecionarem, embora de forma variável, um dos ingredientes das dietas, no caso, o concentrado. O teor de FDN do alimento é inversamente relacionado com o consumo (Van Soest, 1994). No entanto, neste experimento a queda mais acentuada do consumo foi observada somente no nível mais alto de fibra (43\%), e foi relativamente menos variável com o aumento da FDN de 21 para $29 \%$. Por sua vez, a variação do consumo dos demais componentes refletiu a variação de suas concentrações nas dietas.

A digestibilidade da FDN não foi influenciada $(\mathrm{P}>0,05)$, mas a digestibilidade aparente da MS e da MO diminuíram linearmente $(\mathrm{P}<0,01)$ com o aumento de fibra na dieta (Tab.3). Suplementação com concentrado normalmente diminui o consumo e a digestibilidade do volumoso (Mertens e Loften, 1980; Chase e
Hibberd, 1987; Cronje, 1992; Itavo et al., 2002), principalmente por reduzir o $\mathrm{pH}$ ruminal a valores abaixo de 6,0 (Mould e Orskov, 1983; Mourino et al., 2001). No presente experimento, no entanto, os valores de $\mathrm{pH}$ foram sempre acima de 6,5 (Fig. 1) e, deste modo, não representou um fator limitante para a digestão da forragem. A redução da digestibilidade da MS e MO está associada à redução no consumo de CNF e ao aumento no consumo de FDN. Os CNF normalmente são totalmente degradados no rúmen ou digeridos ao longo do trato gastrintestinal dos ruminantes. A DVMO também diminuiu linearmente $(\mathrm{P}<0,01)$ com $\mathrm{O}$ aumento da FDN na dieta e foi em média 14\% mais alta que a digestibilidade aparente, indicando uma presença significativa de material endógeno e microbiano nas fezes. Esta diferença é o dobro do fator de desconto (7\%) proposto por Weiss (1993) e utilizado por padrões nutricionais como o CNCPS para calcular o teor de nutrientes digestíveis totais a partir da digestibilidade verdadeira das frações do alimento. Da mesma forma, a digestibilidade verdadeira do $\mathrm{N}$ foi, em média, $17 \%$ mais alta que a aparente e a diferença tendeu a ser maior nas dietas com o mais baixo e mais alto teor de FDN. Na dieta com menos fibra isto pode estar associado ao maior consumo de milho. $\mathrm{O}$ amido e a proteína do milho são mais lentamente e menos extensivamente degradados no rúmen (Sauvant et al., 1985; Ludden e Cecava, 1995; Zeoula et al., 1999). Deste modo, é provável que maior quantidade dessas frações tenha alcançado $\mathrm{o}$ intestino delgado e grosso nesta dieta. $\mathrm{O}$ aumento da disponibilidade de substratos no intestino aumenta a fermentação e o crescimento bacteriano nestes compartimentos, aumenta as perdas fecais metabólicas e diminui a digestibilidade aparente (Van Soest, 1994). De outra forma, a relativamente alta diferença entre digestibilidade aparente e real do $\mathrm{N}$ da dieta com $43 \%$ de FDN provavelmente foi devido à sua menor digestibilidade da MS, uma vez que a excreção de $\mathrm{N}$ metabólico fecal parece ser diretamente proporcional ao consumo de MS indigestível (Nutrient..., 1996). 
Níveis de fibra em detergente neutro na dieta...

Tabela 3. Consumo e digestibilidade dos compostos não nitrogenados em borregos que consumiram dietas com diferentes teores de fibra em detergente neutro (FDN)

\begin{tabular}{|c|c|c|c|c|c|c|}
\hline \multicolumn{7}{|c|}{ Tratamentos ( $\%$ de FDN na MS) } \\
\hline FDN pretendido & $25 \%$ & $31 \%$ & $37 \%$ & $43 \%$ & $\mathrm{DP}^{1}$ & $\mathrm{P}^{2}$ \\
\hline FDN obtido & $21 \%$ & $26 \%$ & $29 \%$ & $43 \%$ & & \\
\hline Silagem:concentrado ${ }^{3}$ & $21: 79$ & $32: 68$ & 39:61 & $68: 32$ & & \\
\hline \multicolumn{7}{|l|}{ Consumo de MS: } \\
\hline Total (g/dia) & 944 & 859 & 971 & 730 & 129 & * \\
\hline$\% \mathrm{pv}$ & 2,66 & 2,40 & 2,70 & 2,03 & 0,37 & $*$ \\
\hline \multicolumn{7}{|l|}{ Consumo de MO: } \\
\hline Total (g/dia) & 897 & 812 & 913 & 685 & 122 & * \\
\hline $\mathrm{g} / \mathrm{kg} \mathrm{pv} v^{0.75}$ & 61,7 & 55,7 & 62,4 & 46,8 & 8,5 & * \\
\hline \multicolumn{7}{|l|}{ Consumo total (g/dia): } \\
\hline FDN & 200 & 222 & 282 & 317 & 40 & $* *$ \\
\hline $\mathrm{CNF}$ & 517 & 409 & 405 & 236 & 65 & $* *$ \\
\hline \multicolumn{7}{|c|}{ Digestibilidade aparente (\%): } \\
\hline MS & 76 & 73 & 68 & 59 & 4 & $* *$ \\
\hline MO & 78 & 74 & 69 & 61 & 4 & $* *$ \\
\hline FDN & 43 & 41 & 36 & 40 & 8 & ns \\
\hline \multicolumn{7}{|c|}{ Digestibilidade verdadeira da MO (\%): } \\
\hline & 87 & 84 & 80 & 72 & 2 & $* *$ \\
\hline
\end{tabular}

${ }^{1}$ Desvio padrão das médias, onde $\mathrm{n}=8$ por tratamento.

${ }^{2}$ Probabilidade (erro Tipo I) do efeito linear, onde: $*=\mathrm{P}<0,05 ; * *=\mathrm{P}<0,01$ e ns=não significativo.

${ }^{3}$ Proporção volumoso:concentrado consumido (base matéria seca) calculado com base nos teores de FDN da silagem e dos respectivos concentrados.

Tabela 4. Consumo e digestibilidade do nitrogênio $(\mathrm{N})$, e síntese de proteína microbiana ruminal em borregos consumindo dietas com diferentes teores de fibra em detergente neutro (FDN)

\begin{tabular}{|c|c|c|c|c|c|c|}
\hline \multicolumn{4}{|c|}{ Tratamentos ( $\%$ de FDN na MS) } & \multirow[b]{2}{*}{ DP } & \multicolumn{2}{|c|}{$\mathrm{P}^{1}$} \\
\hline $21 \%$ & $26 \%$ & $29 \%$ & $43 \%$ & & $\mathrm{~L}$ & $\mathrm{Q}$ \\
\hline \multicolumn{7}{|c|}{ Consumo total (g/dia): } \\
\hline 26 & 27 & 35 & 20 & 4 & ns & $* *$ \\
\hline \multicolumn{7}{|c|}{ Digestibilidade aparente (\%): } \\
\hline 78 & 82 & 79 & 74 & 4 & $*$ & ns \\
\hline \multicolumn{7}{|c|}{ Digestibilidade verdadeira (\%): } \\
\hline 96 & 96 & 95 & 94 & 2 & $* *$ & ns \\
\hline \multicolumn{7}{|c|}{ Síntese microbiana ruminal $(\mathrm{g} / \mathrm{dia})^{2}$ : } \\
\hline 9,4 & 10,6 & 13,6 & 9,7 & 3,9 & ns & $*$ \\
\hline \multicolumn{7}{|c|}{ Eficiência de síntese protéica microbiana ruminal(g de $\mathrm{Nm} / \mathrm{kg}$ de $\mathrm{MO}$ digestível): } \\
\hline 11,8 & 18,6 & 18,7 & 20,0 & 8,3 & ns & ns \\
\hline
\end{tabular}

Neste experimento, o fluxo de proteína microbiana para o intestino delgado foi mais relacionado com a concentração ruminal de amônia $(\mathrm{r}=0,84)$ e aminoácidos $(\mathrm{r}=0,53)$ do que com o consumo de MO digestível $(\mathrm{r}=0,20)$. Além disso, a eficiência microbiana ruminal aumenta com o aumento do teor de fibra da dieta (Clark et al., 1992) e, até um determinado nível, com a disponibilidade de peptídios às bactérias (Russell et al., 1992). A eficiência da síntese protéica microbiana ruminal foi bem inferior às demais na dieta com menor teor de fibra e, embora não significativo $(\mathrm{P}=0,15)$, tendeu a aumentar com o aumento do teor de FDN. Os sistemas nutricionais mais recentes, como o CNCPS para bovinos (Fox et al., 2004) e ovinos (Cannas et al., 2004) estabeleceram que níveis de FDN efetivo inferiores a $20 \%$ influenciam negativamente a síntese de proteína microbiana, principalmente por reduzir o $\mathrm{pH}$ ruminal a níveis abaixo de 6,0. De fato, na dieta com menor teor de fibra $(21 \%$ de FDN total) certamente o conteúdo de FDN efetivo foi menor que $20 \%$, uma vez que parte significativa desta fibra estava presente no concentrado. No entanto, como já mencionado anteriormente, os valores de $\mathrm{pH}$ 


\section{Kozloski et al.}

ruminal mantiveram-se relativamente altos em todas as dietas.

É possível então, de outra forma, que a relativamente baixa eficiência microbiana verificada na dieta com menor fibra tenha sido resultado do consumo de milho. Como visto anteriormente, o amido e a proteína do milho são mais lentamente e menos extensivamente degradados no rúmen. Deste modo, é possível que parte significativa da MO tenha sido digerida nos intestinos, reduzindo a disponibilidade de substratos para as bactérias do rúmen. Esta possibilidade é evidenciada também pelas variáveis que caracterizam a fermentação ruminal (Tab. 5).

Tabela 5. pH e concentrações (mg/dl) de nitrogênio amoniacal (amônia-N), açúcares, aminoácidos e peptídios no fluído ruminal de borregos que receberam dietas com diferentes níveis de fibra em detergente neutro

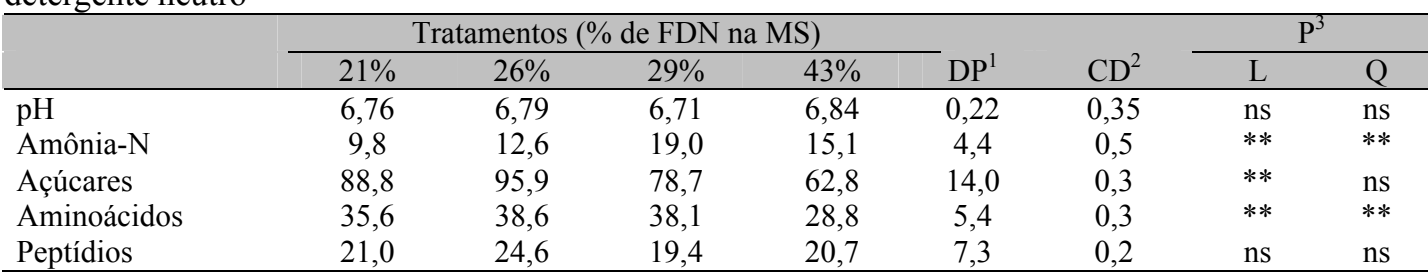

${ }^{1}$ Desvio padrão das médias, onde $\mathrm{n}=4$ por tratamento.

${ }^{2}$ Coeficiente de determinação $\left(\mathrm{r}^{2}\right)$ da regressão.

Probabilidade (erro Tipo I) do efeito linear (L) ou quadrático (Q): ${ }^{* *}=\mathrm{P}<0,01 \mathrm{e}$ ns=não significativo.

As concentrações ruminais de amônia e aminoácidos variaram quadraticamente $(\mathrm{P}<0,01)$ com o aumento do teor de fibra das dietas, sendo mais baixas nas dietas com mais baixo e mais alto teor de fibra, e máximas nos níveis de 26 e $29 \%$ de FDN,respectivamente. De outra forma, as concentrações de açúcares diminuíram linearmente $(\mathrm{P}<0,01)$ e os valores de $\mathrm{pH}$, assim como as concentrações de peptídeos no fluído ruminal, foram similares em todos os tratamentos $(\mathrm{P}>0,05)$.

Era esperada uma queda significativa no $\mathrm{pH}$ médio do rúmen com a diminuição dos níveis de FDN das dietas. No entanto, como já comentado anteriormente, mesmo nos níveis mais baixos de fibra o pH ruminal manteve-se em valores relativamente altos, bem acima do limite mínimo associado com a queda na degradação da fibra no rúmen. A queda do teor de açúcares no fluído ruminal com o aumento da FDN na dieta provavelmente está associada à diminuição da disponibilidade ruminal de carboidratos não estruturais, como o amido, cuja taxa e extensão da degradação são mais altas que os carboidratos presentes na fibra. A concentração de amônia no fluído ruminal, por sua vez, e sua relação com o teor de FDN da dieta, podem estar relacionadas não só com a variação na proporção volumoso:concentrado, mas também com a variação na composição do concentrado das dietas. É conhecido que a taxa de degradação ruminal da proteína (e de liberação de amônia no rúmen) do farelo de soja é mais alta que do milho e que da silagem de sorgo (Sauvant et al., 1985; Ludden e Cecava, 1995). À medida que aumentou o teor de FDN, aumentou a proporção de farelo de soja do concentrado e aumentou também a relação volumoso:concentrado da dieta. É provável, então, que o aumento da inclusão de farelo de soja tenha determinado um aumento nas concentrações de amônia ruminal até um determinado limite onde este efeito tenha sido contrabalanceado pelo aumento da proporção do volumoso na dieta.

As concentrações de peptídios não variaram significativamente $(\mathrm{P}>0,05)$, mas o $\mathrm{pH}$ diminuiu $\mathrm{e}$ as concentrações de amônia, açúcares e aminoácidos aumentaram nas primeiras horas após a refeição e, a seguir, tenderam todos a retornar novamente aos valores pré-alimentares (efeito quadrático, $\mathrm{P}<0,05$ ) (Fig. 1).

O consumo de energia total e digestível, assim como a digestibilidade da energia, o teor de energia digestível e o teor de NDT das dietas diminuíram linearmente com o aumento da fibra do alimento $(\mathrm{P}<0,05, \mathrm{P}<0,01, \mathrm{P}<0,01, \mathrm{P}<0,01 \mathrm{e}$ $\mathrm{P}<0,01$, respectivamente) (Tab. 6). 


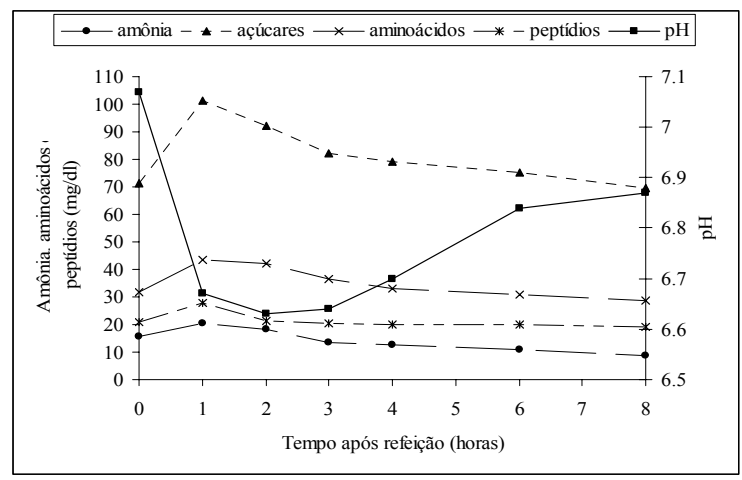

Figura 1. Variação do pH e das concentrações de amônia, açúcares, aminoácidos e peptídios do fluído ruminal de borregos que receberam dietas com diferentes níveis de fibra em detergente neutro.

Tabela 6. Consumo e digestibilidade da energia em borregos que consumiram dietas com diferentes teores de fibra em detergente neutro

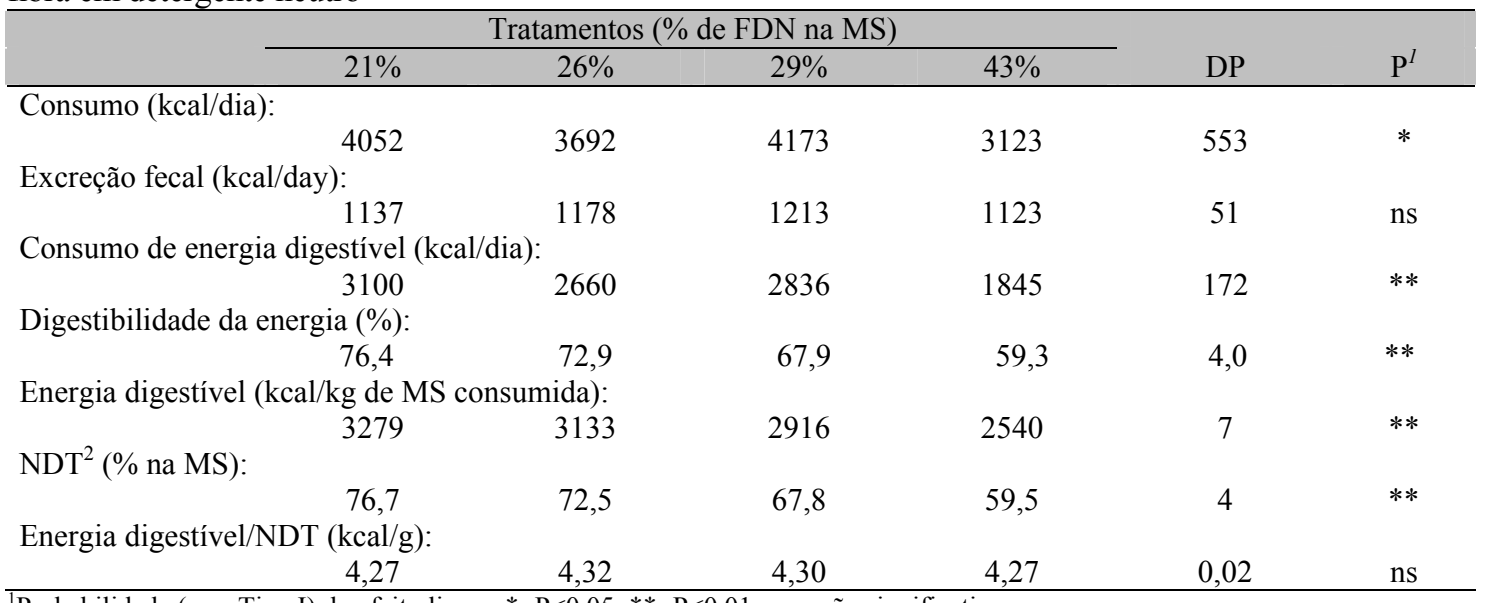

${ }^{1}$ Probabilidade (erro Tipo I) do efeito linear, $*=\mathrm{P}<0,05 ; * *=\mathrm{P}<0,01$ e ns=não significativo.

${ }^{2}$ Nutrientes digestíveis totais $(\mathrm{NDT}=$ proteína bruta + carboidratos totais + gordura digestíveis)

No entanto, o teor de energia digestível por unidade de NDT foi similar em todos os tratamentos.O consumo e a digestibilidade da energia, assim como o teor calculado de NDT das dietas, refletiram o consumo e a digestibilidade da MO. O teor de energia digestível por unidade de NDT foi em média $4,3 \mathrm{kcal} / \mathrm{g}$, muito próximo do valor proposto por Weiss (1993) para estimar o teor de energia digestível dos alimentos para ruminantes a partir do NDT $(4,4 \mathrm{kcal} / \mathrm{g}$ de NDT).

\section{CONCLUSÃo}

$\mathrm{O}$ aumento do teor de fibra (FDN) diminuiu o consumo de alimento e a oferta total de nutrientes ao animal, mas não influenciou a digestão da fibra. No entanto, a redução do consumo e digestibilidade foram mais evidentes somente pela inclusão do nível mais alto de FDN (43\%). Deste modo, sob o aspecto nutricional, a inclusão em torno de $30 \%$ de FDN representa o nível mais adequado para formulação de dietas a base de silagem de sorgo e concentrado fornecido para cordeiros confinados.

\section{REFERÊNCIAS BIBLIOGRÁFICAS}

CANNAS, A.; TEDESCHI, L.O.; FOX, D.G. et al. A mechanistic model for predicting the nutrient requirements and feed biological values for sheep. $J$. Anim. Sci., v.82, p. 149-169, 2004.

CHASE, C.C.; HIBBERD, C.A. Utilization of lowquality native grass hay by beef cows fed increasing quantities of corn grain. J. Anim. Sci., v.65, p.557-566, 1987. 


\section{Kozloski et al.}

CHEN, X.B.; GOMES, M.J. Estimation of microbial protein supply to sheep and cattle based on urinary excretion of purine derivatives - An overview of the technical details. Bucksburn Aberdeen: Rowett Research Institute (Occasional Publication), 1995. 21 p.

CLARK, J. H.; KLUSMEYER, T. H.; CAMERON, M. R. Microbial protein synthesis and flows of nitrogen fractions to the duodenum of dairy cows. $J$. Dairy Sci., v.75, p.2304-2323, 1992.

CRONJÉ, P.B. Effect of dietary roughage:concentrate ratio and rumen ammonia concentration on in situ feedstuff degradation in the rumen of sheep. South Afric. J. Anim. Sci., v.22, p. 207-213, 1992.

DUBOIS, M.; GILLES, K.A.; HAMILTON, J.K. et al. Colorimetric method for determination of sugars and related substances. Anal. Chem., v.28, p.350-356, 1956.

ERDMAN, R. A.; PROCTOR, G. H.;VANDERSALL, J. H. Effect of rumen ammonia concentration on in situ rate and extent of digestion of feedstuffs. J. Dairy Sci. v.69, p.2312-2320, 1986.

FOX, D.G.; TEDESCHI, L.O.; TYLUTKI, T.P. et al. The Cornell Net Carbohydrate and Protein System model for evaluating herd nutrition and nutrient excretion. Anim. Feed Sci. Technol., v.112, p.29-78, 2004.

GRANT, R.J.; MERTENS, D.R. influence of buffer $\mathrm{pH}$ and raw corn starch addition on in vitro fiber digestion kinetics. J. Dairy Sci., v.75, p.2762-2768, 1992.

ITAVO, L.C.V.; VALADARES FILHO, S.C.; SILVA, F.F. Níveis de concentrado e proteína bruta na dieta de bovines Nelore nas fases de recria e terminação: consumo e digestibilidade. Rev. Bras. Zootec., v.31, p.1033-1041, 2002.

LICITRA, G.; HERNANDEZ, T.M.; VAN SOEST, P.J. Standartization of procedures for nitrogen fractionation of ruminant feeds. Anim. Feed Sci. Technol., v.57, p.347-358, 1996.

LUDDEN, P.A.; CECAVA, M.J. Supplemental protein sources for steers fed corn-based diets: I. Ruminal characteristics and intestinal amino acid flows. J. Anim. Sci., v.73, p.1466-1475, 1995.

MERTENS, D.R.; LOFTEN, J.R. The effect of starch on forage fiber digestion kinetics in vitro. J. Dairy Sci., v.63, p.1437-1446, 1980

MOULD, F.L.; ØRSKOV, E.R. Manipulation of rumen fluid $\mathrm{pH}$ and its influence on cellulolysis in sacco, dry matter degradation and the rumen microflora of sheep offered either hay or concentrate. Anim. Feed Sci. Technol., v.10, p.1-14, 1983.
MOURIÑO, F.; AKKARAWONGSA, R.A.; WEIMER, P.J. Initial $\mathrm{pH}$ as a determinant of cellulose digestion rate by mixed ruminal microorganisms in vitro. J. Dairy Sci. v.84, p.848-859, 2001.

NUTRIENT requirements of beef cattle. 7.ed. Washington: National Academy of Sciences, 1996. $381 \mathrm{p}$.

NUTRIENT requirements of dairy cattle. 7.ed. Washington: National Academy of Sciences, 2001. $381 \mathrm{p}$.

OFFICIAL methods of analysis. 16.ed. Washington: AOAC, 1995. 186p.

PALMER, D. W.; PETERS JR., T. Automated determination of free amino groups in serum and plasma using 2,4,6 trinitro-benzene sulfonate. Clin. Chem., v.15, p.891-901, 1969.

PIRES, C. C. Cria e terminação de cordeiros confinados. Ciência Rural, v.30, p.875-880, 2000.

ROBERTSON, J. B.; VAN SOEST, P. J. The detergent system of analysis. In: JAMES, W.P.T., THEANDER, O. (eds.). The analysis of dietary fibre in food. New York: Marcel Dekker, 1981. p.123-158.

RUSSELL, J. B.; O'CONNOR, J. D.; FOX, D. G. et al. A net carbohydrate and protein system for evaluating cattle diets: I. Ruminal fermentation. $J$. Anim. Sci., v.70, p.3551-3561, 1992.

SAUVANT, D.; BERTRAND, D.; GIGER, S. Variation and prevision of the in sacco dry matter digestion of concentrates and by products. Anim. Feed Sci. Technol., v.13, p.7-23,1985.

TRIPATHI, M.K.; SANTRA, A.; CHATURVEDI, O.H. Effect of sodium bicarbonate supplementation on ruminal fluid $\mathrm{pH}$, feed intake, nutrient utilization and growth of lambs fed high concentrate diets. Anim. Feed Sci. Technol., v.111, p.27-39, 2004.

USER'S guide: statistical analysis system. Realese 6.11. Cary, NC: SAS Institute, 1996.

VAN SOEST, P. J. Nutritional Ecology of the Ruminant. 2.ed. New York: Cornell University Press, 1994. $476 \mathrm{p}$.

WEATHERBURN, M.W. 1967. Phenol-hypochlorite reaction for determination of ammonia. Anal. Chem., v.39, p.971-974, 1967.

WEISS, W.P. Predicting energy values of feeds. $J$. Dairy Sci., v.76, p.1802-1811, 1993.

ZEOULA, L.M.; MARTINS, A.S.; PRADO, I.N. et al. Solubilidade e degradabilidade ruminal do amido de diferentes alimentos. Rev. Bras. Zootec., v.28, p.898$905,1999$. 